\title{
Metabolism of Vitamin D. I. Preparation of Radioactive Vitamin D and Its Intestinal Absorption in the Rat *
}

\author{
David Schachter, $\nmid$ James D. Finkelstein, $\ddagger$ and Szloma Kowarski \\ (From the Department of Medicine, Columbia University College of Physicians \& Surgeons, \\ and the Presbyterian Hospital, New York, N.Y.)
}

Vitamin D has been called "the most dominating single factor in the regulation of the absorption of calcium" (1). Although experiments with segments of small intestine in vitro have demonstrated that the vitamin is required to maintain an active transport mechanism for calcium in the mucosa $(2-4)$, the molecular events underlying the action remain unknown. To define them, detailed information on the metabolism of vitamin $\mathrm{D}$, now lacking, is needed.

The metabolic fate of the vitamins $\mathrm{D}$ can be studied most effectively with radioactive compounds, for chemical methods of estimation are relatively insensitive or nonspecific, and biological assay is tedious and difficult. $\mathrm{C}^{14}$-vitamin $\mathrm{D}_{3}$ labeled at $\mathrm{C}_{3}(5)$ and randomly labeled $\mathrm{C}^{14}$-vitamin $\mathrm{D}_{2}$ (6) have been prepared by prior investigators, and with the latter material Kodicek and collaborators have provided much of the available metabolic data $(7-10)$. The information remains limited, however, partly because it is difficult to prepare sufficient quantities of material of relatively high specific activity. Accordingly, the present studies were begun to develop more efficient methods for the preparation of radioactive vitamin $\mathrm{D}$ for metabolic studies. Tritium-labeled vitamin $\mathrm{D}_{3}$ and $C^{14}$-labeled vitamin $\mathrm{D}_{2}$ have been prepared, and the major pathways of transport and metabo-

* Submitted for publication October 28, 1963 ; accepted December 26, 1963.

Supported by U. S. Public Health Service grant AM01483.

Portions of this work were presented at the 55th Annual Meeting of the American Society for Clinical Investigation, Atlantic City, N. J., April 1963.

† Investigator, New York City Health Research Council (contract I-183). Supported in part by a National Institutes of Health general research support grant.

$¥$ U. S. Public Health Service trainee. Present address: National Institute of Arthritis and Metabolic Diseases, Bethesda, Md. lism in the rat identified (11). Vitamin D is absorbed chiefly into lymph, distributed widely in the tissues but accumulated in highest concentration in liver, and excreted mainly into bile. The present report describes in detail the preparation of the radioactive compounds and their intestinal absorption in the rat.

\section{Materials and Methods}

Preparation of $H^{3}$-vitamin $D_{3}$. Initial experiments demonstrated persistence of biological activity in a solution of vitamin $\mathrm{D}_{3}$ in $80 \%$ acetic acid after 16 hours at $23^{\circ} \mathrm{C}$ in an atmosphere of $\mathrm{N}_{2}$. Therefore $1 \mathrm{~g}$ of crystalline vitamin $D_{3}$ under $N_{2}{ }^{1}$ was labeled ${ }^{2}$ by catalytic exchange in tritiated acetic acid under identical conditions (schedule TR-1). The product, a brownish material in a vial under $\mathrm{N}_{2}$, was applied for thin-layer chromatography on plates of activated silicic acid gel $^{3} 0.5 \mathrm{~mm}$ thick. Reference vitamin $D_{3}$ was applied to the outer margins. The plates were developed in the dark for 45 minutes with $\mathrm{CHCl}_{3}$ as the solvent, dried briefly at room temperature, sprayed lightly with $0.001 \%$ Rhodamine $6 \mathrm{G}$ in acetone, and viewed under an ultraviolet lamp (maximal emission, $253.7 \mathrm{~m} \mu$ ) to localize the dark, absorbing band of vitamin $\mathrm{D}_{3}$. The bands of gel were scraped from the plates and eluted repeatedly with $\mathrm{CHCl}_{3}$. Vi$\operatorname{tamin} \mathrm{D}$ in the eluate, and generally in the present studies, was estimated chemically with an $\mathrm{SbCl}_{3}$ reagent (12). (Dried samples were treated with the $\mathrm{SbCl}_{3}$ reagent at room temperature for exactly 1 minute and the optical density at $500 \mathrm{~m} \mu$ determined immediately in a Beckman model DU spectrophotometer in cuvettes of 10 mm light path). The combined $\mathrm{CHCl}_{3}$ eluates, containing $294 \mathrm{mg}$ of $\mathrm{SbCl}_{3}$-reactive material, were evaporated to dryness at 25 to $30^{\circ} \mathrm{C}$ under a stream of $\mathrm{N}_{2}$, and the residue was dissolved in $8 \mathrm{ml}$ of dry pyridine. To esterify the vitamin, $350 \mathrm{mg}$ of powdered 3,5-dinitrobenzoyl chloride was added and the mixture kept under $\mathrm{N}_{2}$, in the dark, at room temperature. After 20 hours another 100 $\mathrm{mg}$ of dinitrobenzoyl chloride was added and the mixture kept for 2 more days. It was then added dropwise

\footnotetext{
1 Mann Research Laboratories, New York, N. Y.

2 By the Nuclear-Chicago Corp., Des Plaines, Ill.

${ }^{3}$ Silica Gel G, Brinkmann Instruments, Great Neck,
} N. Y. 
to $20 \mathrm{ml}$ of $0.1 \mathrm{~N} \mathrm{NaHCO}_{3}$, and the resulting yellow precipitate was washed three times with water to remove all pyridine odor, dried under a $\mathrm{N}_{2}$ stream, dissolved in $4 \mathrm{ml}$ of warm acetone, and filtered. After addition of 4 $\mathrm{ml}$ of methanol and cooling, yellow crystals of dinitrobenzoyl-vitamin $\mathrm{D}_{3}$ were harvested and recrystallized from acetone/methanol $(1 / 1, \mathrm{vol} / \mathrm{vol})$. The dried product, 102 $\mathrm{mg}$ of ester, and ester prepared similarly from crystalline vitamin $\mathrm{D}_{3}$ gave identical melting points: 128 to $129^{\circ} \mathrm{C}$ (cloudy melt) (13) and $133^{\circ} \mathrm{C}$ (clear melt). Melting points were determined with a Fisher-Johns apparatus ${ }^{4}$ and corrected with crystalline reference compounds. The tritium content of the ester, and $\mathrm{H}^{3}$ and $\mathrm{C}^{14}$ generally in these studies, were measured in a Packard Tri-Carb liquid scintillation spectrometer in glass vials containing $15 \mathrm{ml}$ of a standard toluene scintillator solution (14), or Bray's solution (15) for water-soluble samples. All counts were corrected for self-absorption by addition of an internal standard: $\mathrm{H}^{3}$-toluene, $\mathrm{C}^{\mathbf{1 4}}$-toluene, or $\mathrm{H}^{3}-\mathrm{H}_{2} \mathrm{O}$. The specific activity of the $\mathrm{H}^{3}$-vitamin $\mathrm{D}_{3}$ dinitrobenzoyl ester was $6,650 \mathrm{dpm}$ per $\mu \mathrm{g}$, corresponding to $247 \mathrm{dpm}$ per IU vitamin D.

The radioactive ester was hydrolyzed before metabolic studies by crushing approximately $300 \mu \mathrm{g}$ of crystals in 0.3 to $0.4 \mathrm{ml}$ of $2 \% \mathrm{KOH}$ in $98 \%$ ethanol. The tube was flushed with $\mathrm{N}_{2}$ and incubated in the dark at $47^{\circ} \mathrm{C}$ for 2 hours. The resulting hydrolysate was adjusted to $\mathrm{pH}$ 8 with glacial acetic acid, the free vitamin extracted with 10 vol of $\mathrm{CHCl}_{3}$, and the extract applied to a silicic acid gel plate for thin-layer chromatography as described above. The $\mathrm{H}^{3}$-vitamin $\mathrm{D}_{3}$ band was eluted with $\mathrm{CHCl}_{3}$, assayed for radioactivity, and the $\mathrm{CHCl}_{3}$ solution stored under $\mathrm{N}_{2}$ at $-15^{\circ} \mathrm{C}$ in the dark when not used immediately. (Batches of the free vitamin were usually used within 2 to 4 days of their preparation. When the vitamin was stored for 7 or more days, traces of breakdown products appeared on thin-layer chromatography, and the material was rechromatographed before use.) The $\mathrm{H}^{3}$-vitamin $\mathrm{D}_{3}$ prepared in this manner was tested at three dosage levels for biological activity with the duodenal slice assay $(4,16)$ and crystalline vitamin $D_{3}$ as reference standard. The data in Figure 1 indicate that the radioactive vitamin is fully active. Chemical purity of the $\mathrm{H}^{3}$-vitamin $\mathrm{D}_{3}$ was assessed further by gas-liquid chromatography, using a Barber-Colman model 15 apparatus with an argon ionization detector and radium cathode. The 6-foot $\times 4$-mm column was packed with $1 \%$ SE-30 silicone on 110 to 120 mesh Anakron $\mathrm{ABS}^{5}$ and maintained at $230^{\circ} \mathrm{C}$ (flash heater, $275^{\circ} \mathrm{C}$; detector cell, $265^{\circ} \mathrm{C} ; 30$ pounds per square inch). The radioactive vitamin and a crystalline reference standard gave identical results, the characteristic two-peaked curves (presumably pyro- and isopyro-vitamin $\mathrm{D}_{3}$ ) reported previously (17).

Preparation of $C^{14}$-vitamin $D_{2}$. Uniformly labeled $C^{14}$ vitamin $D_{2}$ was prepared biosynthetically by the method of

${ }^{4}$ Fisher Scientific Co., New York, N. Y.

5 Analabs, Hamden, Conn.

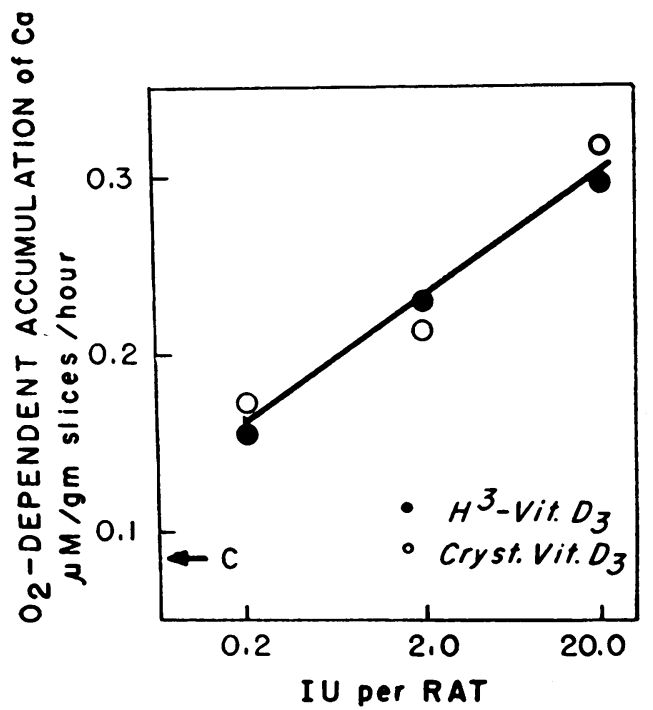

Fig. 1. Bioassay of $\mathrm{H}^{3}$-vitamin $\mathrm{D}_{3}$. The $\mathrm{H}^{3}$-vitamin $D_{3}$ and crystalline vitamin $D_{3}$ were tested at three dose levels, each dose fed to each of 8 rats depleted of vitamin D (16). Duodenal slices were prepared and tested for accumulation of $\mathrm{Ca}^{4 \pi}$ in vitro 48 hours later, as previously described (4). C = value observed with depleted rats fed no vitamin $D$.

Kodicek (6) modified as follows. A small inoculum of $S$. cerevisiae $^{6}$ was incubated aerobically in $25 \mathrm{ml}$ of medium of the following composition : $2 \%$ glucose, $0.1 \mathrm{M}$ potassium phosphate of $\mathrm{pH} 5.3,0.01 \mathrm{M}$ sodium acetate of $\mathrm{pH} 5.3$, $0.1 \% \mathrm{NH}_{4} \mathrm{Cl}, 0.1 \%$ yeast extract, ${ }^{7} 0.03 \% \mathrm{MgSO}_{4} \cdot 7 \mathrm{H}_{2} \mathrm{O}$, $0.005 \% \mathrm{ZnSO}_{4} \cdot 7 \mathrm{H}_{2} \mathrm{O}$, and $0.005 \% \mathrm{FeSO}_{4} \cdot 7 \mathrm{H}_{2} \mathrm{O}$. After 24 hours at room temperature the incubation mixture was added to $400 \mathrm{ml}$ of identical medium containing $0.5 \mathrm{mc}$ of acetate-2- $\mathrm{C}^{14} .8$ A stream of $\mathrm{O}_{2}$ was passed through the mixture, $\mathrm{CO}_{2}$ was trapped in alkali, and the culture was incubated for 24 hours at $32^{\circ} \mathrm{C}$. After the yeast was harvested by centrifugation, the precipitate was washed three times with water and then triturated with $12 \mathrm{ml}$ of glacial acetic acid for 1 hour at $70^{\circ}$ to increase the yield of $\mathrm{C}^{14}$-ergosterol (18). After lyophilization, the dried yeast was extracted for 36 hours in a Soxhlet apparatus, using a fresh charge of $150 \mathrm{ml}$ acetone every 12 hours. The acetone extract was evaporated, the residue saponified in $6 \%$ ethanolic $\mathrm{KOH}$ (18 hours, $23^{\circ} \mathrm{C}$, under $\mathrm{N}_{2}$, in the dark), and the nonsaponifiable fraction extracted into petroleum ether. After evaporation of the petroleum ether, the residue was dissolved in a small volume of ethanol, $2.0 \mathrm{mg}$ of carrier ergosterol added, and the $\mathrm{C}^{14}$ ergosterol precipitated as the digitonide. The digitonide was decomposed with pyridine (19) and the free sterol

${ }^{6} \mathrm{We}$ are indebted to Dr. Margarita Silva for the pure culture of $S$. cerevisiae.

7 Difco Laboratories, Detroit, Mich.

8 New England Nuclear Corp., Boston, Mass. 
extracted into ethyl ether. Dry, peroxide-free solutions of $\mathrm{C}^{14}$-ergosterol in ethyl ether were irradiated in a quartz cuvette, under $\mathrm{N}_{2}$, using a mercury arc lamp ${ }^{9}$ at a distance of 10 to $12 \mathrm{~cm}$ and an interference filter 10 with maximal transmission at $290 \mathrm{~m} \mu$. After 40 to $50 \%$ conversion of the ergosterol, as judged by the $\mathrm{SbCl}_{3}$ reaction, the ether was evaporated under $\mathrm{N}_{2}$; the residue was dissolved in benzene and maintained at $60^{\circ} \mathrm{C}$ for 2 hours under $\mathrm{N}_{2}$ to convert previtamin $\mathrm{D}_{2}$ to vitamin $\mathrm{D}_{2}$ (20). The solution was then applied to silicic acid gel plates for thin-layer chromatography as described above, except that benzene/ethyl acetate $(5 / 1)$ was the developing solvent (21). Ergosterol, vitamin $D_{2}$, and other products of irradiation were clearly separated as absorbing bands on the plates, the individual bands eluted with $\mathrm{CHCl}_{3}$, and the $\mathrm{C}^{14}$-ergosterol reirradiated. Finally, the combined $\mathrm{C}^{14}$-vitamin $\mathrm{D}_{2}$ eluates were evaporated, and the residue was dissolved in dry pyridine and esterified with 3,5-dinitrobenzoyl chloride as described above. Subsequently $13 \mathrm{mg}$ of carrier, crystalline dinitrobenzoyl-vitamin $D_{2}$ was added and the ester crystallized from acetone/methanol $(1 / 1, \mathrm{vol} / \mathrm{vol})$. The recrystallized dried product, $10 \mathrm{mg}$ of material, melted sharply at $143^{\circ} \mathrm{C}$ (6), as did the authentic ester. The specific activity was $1.1 \mathrm{dpm}$ per IU vitamin $\mathrm{D}$. In a second preparation $\mathrm{C}^{14}$ ergosterol isolated from two batches of yeast was combined, and the specific activity of the resulting $\mathrm{C}^{14}$-vitamin $D_{2}$ was $5.3 \mathrm{dpm}$ per IU. The values are comparable to several reported by Kodicek, $0.5 \mathrm{dpm}$ per IU (6) and $5.5 \mathrm{dpm}$ per IU (22).

Animal experiments. Male albino Sherman rats were used, except in some of the lymph collection experiments where Sprague-Dawley animals gave similar results. For cannulation of the thoracic lymph duct (23) or common bile duct, rats weighing 350 to $400 \mathrm{~g}$ were anesthetized with ether and restrained postoperatively in cages with free access to food ${ }^{11}$ and water. Lymph or bile was collected in vessels chilled in ice; a control collection period of 24 hours preceded each experiment. For oral administration the radioactive sterols were dissolved in a small volume of ethanol and diluted with 5 vol of propylene glycol. Each rat was anesthetized for 2 to 3 minutes with ether and given $0.5 \mathrm{ml}$ by gastric tube. Radioactivity in lymph, feces, and tissues was estimated by homogenizing each sample with at least $25 \mathrm{vol}$ of ethanol/acetone $(1 / 1, \mathrm{vol} / \mathrm{vol})$ for 2 minutes in a Vortis homogenizer. The mixture was filtered, the extract evaporated, and the residue dissolved in the toluene scintillator solution for counting. After decanting the toluene solution, any remaining residue was shaken with $0.5 \mathrm{ml}$ of water and then $15 \mathrm{ml}$ of Bray's solution to count water-soluble radioactivity. (Water-soluble radioactivity generally did not exceed 5 to $10 \%$ of the

\footnotetext{
9 Model QA-450, Burdick Corp., Milton, Wis. 10 Type A-11, Baird-Atomic Inc., Boston, Mass. ${ }^{11}$ Rockland rat diet, A. E. Staley Mfg. Co., Decatur,
} III.

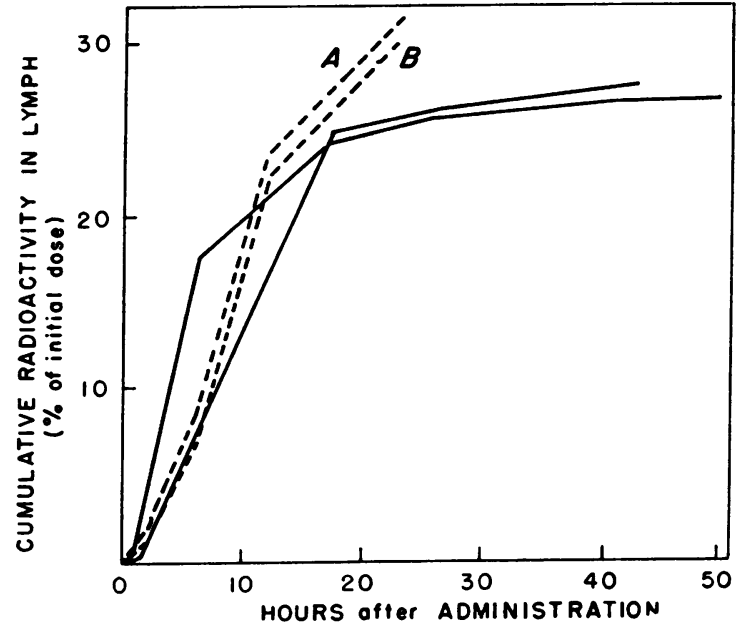

Fig. 2. Cumulative Recovery of Radioactivity iN LYMPH AFTER ORAL ADMINISTRATION OF RADIOACTIVE VITAMIN D. Each solid plot represents one rat given 1.4 $\mathrm{mg}$ of uniformly labeled $\mathrm{C}^{14}$-vitamin $\mathrm{D}_{2}$ in ethanol/ propylene glycol. The broken plots represent a third rat given $0.16 \mathrm{mg}$ of $\mathrm{H}^{3}$-vitamin $\mathrm{D}_{3}$ (A) plus $0.16 \mathrm{mg}$ of $C^{14}$-vitamin $D_{2}(B)$. Samples were usually collected at $\frac{1}{2}$, $1,2,5,10,18,24$, and approximately 40 to 50 hours.

total counts recovered in the present experiments). The recovery of radioactive vitamin $D$ added to lymph, feces, or tissue averaged $93 \%$ with this method.

To prepare loops of intestine for absorption studies, rats were fasted for 18 hours in metabolic cages without access to feces. They were then anesthetized with ether for 10 to 12 minutes, and in this time intestinal segments approximately $8 \mathrm{~cm}$ long were rinsed with $10 \mathrm{ml}$ of isotonic saline and then filled and tied as previously described (24). Each loop was filled with $0.5 \mathrm{ml}$ of solution prepared by dissolving radioactive vitamin in a small volume of ethanol and adding the ethanol through a no. 26 needle, with rapid stirring, to the appropriate volume of $0.02 \mathrm{M}$ sodium taurocholate in $0.85 \% \mathrm{NaCl}$. The resulting solutions were grossly clear. After excision of the loops, the unabsorbed radioactivity was estimated as described above. In each experiment at least two control loops were excised immediately after filling, and their radioactivity was taken as the zero-time value. When duodenal loops were tested, the common bile duct, which enters this segment, was ligated.

Bioassay for vitamin D activity was performed as previously described $(4,16)$. The rats were depleted on the U. S. P. rachitogenic diet $2{ }^{12}$ for 4 to 5 weeks before use. Test and reference standard substances were administered in ethanol/propylene glycol $(1 / 5, \mathrm{vol} / \mathrm{vol})$ by gastric tube, and 48 hours later duodenal slices were tested in vitro for accumulation of $\mathrm{Ca}^{47}$ or $\mathrm{Ca}^{45}$.

Materials. Cholesterol-4-C ${ }^{14}$ was obtained commer-

12 Nutritional Biochemicals Corp., Cleveland, Ohio. 
TABLE I

Fraction of absorbed $\mathrm{H}^{3}$-vitamin $\mathrm{D}_{3}$ recovered in lymph*

\begin{tabular}{cccc}
\hline Rat & Dose & $\begin{array}{c}\text { Fraction } \\
\text { of dose } \\
\text { absorbed }\end{array}$ & $\begin{array}{c}\text { Fraction } \\
\text { ot absorbed } \\
\mathrm{H}^{3} \text {-vitamin } \\
\text { Da in } \\
\text { lymph }\end{array}$ \\
\hline & $\mu g$ & $\%$ & $\%$ \\
2 & 42 & 49.7 & 86.7 \\
3 & 46 & 54.3 & 81.9 \\
4 & 46 & 56.3 & 80.5 \\
5 & 1,039 & 45.8 & 96.7 \\
& 1,041 & 46.3 & 81.2 \\
\hline
\end{tabular}

* Rats weighed 350 to $400 \mathrm{~g}$ and were fed the dose in ethanol/propylene glycol by gastric tube as described in Methods. Fraction of the dose absorbed in 16 to 18 hours is indicated; other conditions are described in the text.

cially. ${ }^{13}$ Samples of purified sodium taurocholate, sodium taurodeoxycholate, and sodium taurochenodeoxycholate were donated. ${ }^{14}$ When not specified, the taurocholate used was commercial bile salt, which appeared to be as effective as the purified compound, as indicated below.

\section{Results}

Absorption into lymph. Vitamin D is absorbed chiefly into lymph; representative results of the cumulative recovery in lymph after administration by gastric tube are illustrated in Figure 2. Each of two rats received $1.4 \mathrm{mg}$ of $\mathrm{C}^{14}$-vitamin $\mathrm{D}_{2}$ in ethanol/propylene glycol, and thereafter $\mathrm{C}^{14}$ was detectable in lymph within 1 hour. Absorption remained relatively slow in the first 2 hours, thereafter became more rapid and linear with time up to 8 to 18 hours, and essentially ceased after 26 hours. A third rat was given $0.16 \mathrm{mg}$ of $\mathrm{C}^{14}$ vitamin $\mathrm{D}_{2}$ plus $0.16 \mathrm{mg}$ of $\mathrm{H}^{3}$-vitamin $\mathrm{D}_{3}$ as a single oral dose, and both isotopes were measured in the lymph (Figure 2). Vitamin $\mathrm{D}_{3}$ was absorbed into lymph more rapidly than vitamin $\mathrm{D}_{2}$, although the curves with time appeared generally similar. The results were confirmed with two other lymph-fistula rats and in the following loop experiment. One jejunal loop was tied in each of 10 rats (weight range, 120 to $165 \mathrm{~g}$ ) and filled with the taurocholate-saline medium containing $9 \mu \mathrm{g}$ of $\mathrm{H}^{3}$-vitamin $\mathrm{D}_{3}$ plus $9 \mu \mathrm{g}$ of $\mathrm{C}^{14}$-vitamin $\mathrm{D}_{2}$. After 6 hours the loops were excised, and estimation of the residual radioactivity indicated

\footnotetext{
${ }^{13}$ New England Nuclear Corp., Boston, Mass.

${ }^{14}$ By Dr. Alan F. Hofmann, Rockefeller Institute, New York, N. Y.
}

that in each instance more vitamin $D_{3}$ had been absorbed than vitamin $D_{2}$. Expressed as a percentage of the initial dose, the mean values for absorption of $\mathrm{D}_{3}$ and $\mathrm{D}_{2}$ were 42.0 and $20.0 \%$, respectively.

Table I summarizes the results of experiments in which the quantity of $\mathrm{H}^{3}$-vitamin $\mathrm{D}_{3}$ absorbed from the gastrointestinal tract was compared with the quantity recovered in the lymph. Each of five lymph-fistula rats received the dose by gastric tube, and after a collection period of 16 to 18 hours, absorption was measured as the difference between the dose administered and the radioactivity recovered in the feces, intestinal contents, and gastrointestinal tract. The data demonstrate that 80.5 to $96.7 \%$ (mean, 85.4) of the radioactivity absorbed can be recovered in the lymph. Two dose levels were tested in this experiment, 42 to $46 \mu \mathrm{g}$ and $1.04 \mathrm{mg}$, and these did not influence significantly either the fraction of the dose absorbed or the percentage of absorbed vitamin recovered in the lymph. Further, no significant saturation of the absorptive mechanism was observed in two loop experiments with $\mathrm{C}^{14}$-vitamin $\mathrm{D}_{2}$ and one experiment with $\mathrm{H}^{3}$-vitamin $\mathrm{D}_{3}$. Jejunal loops in each of five rats were filled with a dose varying from 5 to $500 \mu \mathrm{g}$ of vitamin in a clear solution of $0.04 \mathrm{M}$ sodium taurocholate and $0.85 \%$ saline and excised 6 hours thereafter. The percentage absorbed was not decreased significantly at the higher dose levels in this range.

The radioactivity absorbed into lymph was studied further by isolation of the chylomicron fraction, thin-layer chromatography, and bioassay. Chylomicrons were isolated by layering $2 \mathrm{ml}$ of lymph under $10 \mathrm{ml}$ of $0.85 \% \mathrm{NaCl}$ and centrifuging in a Spinco model L ultracentrifuge (30,$000 \mathrm{rpm}, 60$ minutes, rotor 40). The chylomicrons contained 62.7 to $81.2 \%$ (mean, 72.3 ) of the total radioactivity in four lymph samples after oral $\mathrm{H}^{3}$-vitamin $\mathrm{D}_{3}$ and 72.7 to $79.2 \%$ (mean, 77.3) in three samples after $\mathrm{C}^{14}$-vitamin $\mathrm{D}_{2}$. Most of the vitamin $\mathrm{D}$ in lymph is therefore transported in the chylomicron fraction. ${ }^{15}$

\footnotetext{
15 The $\mathrm{H}^{3}$-vitamin $\mathrm{D}_{3}$ was not present as free lipid in the lymph, since radioactivity could not be extracted directly into hexane. The radioactivity could be extracted only after treatment of the lymph with ethanol-acetone $(1 / 1)$ to denature the proteins.
} 
For thin-layer chromatography ethanol-acetone extracts were made of five lymph samples collected from three rats fed $\mathrm{H}^{3}$-vitamin $\mathrm{D}_{3}$. The extracts were evaporated to dryness under $\mathrm{N}_{2}$ at $23^{\circ} \mathrm{C}$ and the residues dissolved in $\mathrm{CHCl}_{3}$ and applied to silicic acid gel plates. After 45 minutes in the dark with petroleum ether/diethyl ether/glacial acetic acid (80/20/1, vol/vol/vol) as developing solvent to separate the major classes of lipids (25), the plates were dried thoroughly at room temperature for 2 hours. Successive bands of gel were scraped directly into glass counting vials, pulverized finely with glass rods, and shaken vigorously with the toluene scintillator solution for at least 3 minutes before measurement of the radioactivity in the liquid scintillation counter. Recovery of the radioactivity applied averaged $81 \%$ with this method. The free sterol zone $\left(R_{f}, 0.25\right.$ to 0.3$)$ contained 56.7 to $80.2 \%$ (mean, 69.4) of the radioactivity, and a zone corresponding to $R_{\mathbf{f}} 0.95$ contained 12.7 to $28.0 \%$ (mean, 17.5). The latter material has not yet been identified, but that this zone contains sterol esters is interesting. The free sterol bands were eluted with $\mathrm{CHCl}_{3}$ and rechromatographed on silicic acid gel plates with $\mathrm{CHCl}_{3}$ as developing solvent (Methods). The vitamin $\mathrm{D}_{3}$ zone contained 70.6 to $93.8 \%$ (mean, 81.7) of the radioactivity, with no other defined band.

Lymph samples were collected for biological assay from each of two rats, both before and after administration of $\mathrm{H}^{3}$-vitamin $\mathrm{D}_{3}$. The animals were fasted throughout the experiment. Vitamin D activity was estimated by the duodenal slice method $(4,16)$, modified only in that each test animal was given $0.1 \mathrm{ml}$ of lymph or reference standard subcutaneously. The lymph samples collected after $\mathrm{H}^{3}$-vitamin $\mathrm{D}_{3}$ showed a marked increment in vitamin $\mathrm{D}$ activity, corresponding to 78 and $108 \%$, respectively, of the vitamin content estimated from the measured radioactivity. Thus most of the vitamin $\mathrm{D}$ absorbed into lymph was biologically active and present as the free sterol.

Requirement for bile. Indirect evidence provided by several groups of investigators (26-28) indicates that bile is required for adequate absorption of vitamin $D$. The following experiments demonstrate the requirement directly. Rats

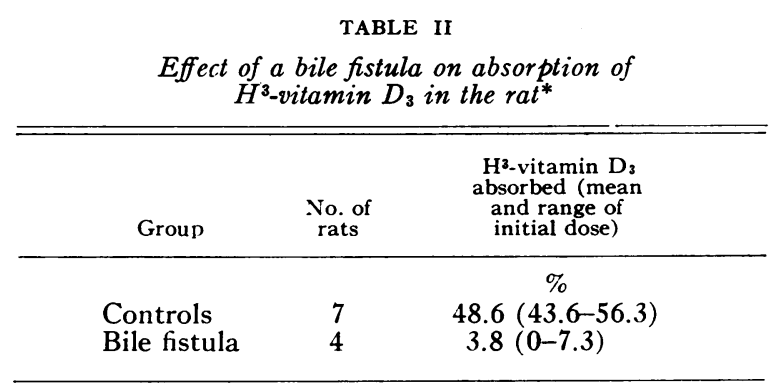

* Each operated or control rat was given approximately $47 \mu$ g of $\mathrm{H}^{3}$-vitamin $\mathrm{D}_{3}$ in ethanol/propylene glycol by gastric tube. Absorption was measured as the difference between the oral dose and the radioactivity recovered in the feces plus intestinal contents, as described in the text.

with draining bile fistulas and intact controls were restrained for approximately 24 hours and then given $\mathrm{H}^{3}$-vitamin $\mathrm{D}_{3}$ by gastric tube. Sixteen hours later they were sacrificed; the residual radioactivity in feces, intestinal contents, and gastrointestinal tract was estimated and absorption calculated as the difference between dose administered and residual radioactivity. The results shown in Table II demonstrate that the bile fistula animals absorbed an average of $3.8 \%$ of the administered dose, whereas the controls absorbed $48.6 \%(\mathrm{p}<0.001)$.

The influence of lipid-solubilizing agents in rats with bile fistulas was then studied. Initial experiments, in which the animals were fed a single dose of $\mathrm{H}^{3}$-vitamin $\mathrm{D}_{3}$ with or without $1.0 \mathrm{ml}$ of fresh rat bile, yielded inconsistent results, perhaps because a continuous supply of bile is required at the sites of intestinal absorption. More consistent effects were obtained with the following procedure. After a control period of 24 hours with bile draining freely through the fistula, each rat was anesthetized with ether, and two adjacent, mid-jejunal loops were tied. One loop was filled with a control suspension $\left(\mathrm{H}^{3}\right.$-vitamin $\mathrm{D}_{3}$ dissolved in $0.1 \mathrm{ml}$ ethanol and added to 5 to $10 \mathrm{ml} 0.85 \%$ saline through a no. 26 needle, with vigorous mixing throughout) and the adjacent loop with the test solution (prepared exactly like the control, except that the ethanolic $\mathrm{H}^{3}$-vitamin $\mathrm{D}_{3}$ was added to $0.85 \%$ saline containing $0.04 \mathrm{M}$ bile salt or other compound, with the resulting solutions clear). The loops were excised after 5 hours, and the results are listed in Table III. Sodium taurocholate increased the absorption approximately twofold, and the pure and 


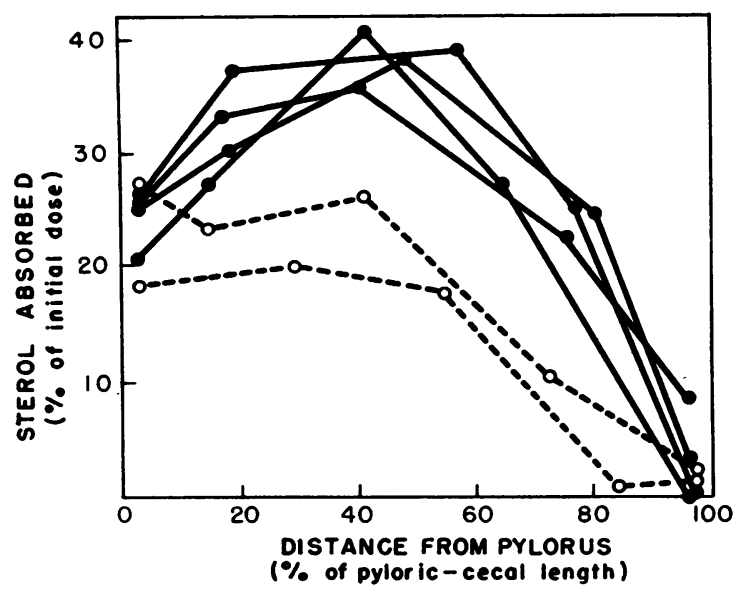

Fig. 3. Absorption of $\mathrm{H}^{3}$-vitamin $\mathrm{D}_{3}$ and $\mathrm{C}^{14}$-choLESTEROL FROM LOOPS OF INTESTINE. Each solid plot represents one rat tested with $\mathrm{H}^{3}$-vitamin $\mathrm{D}_{3}$, and each broken plot one rat tested with $\mathrm{C}^{14}$-cholesterol. Distance from the pylorus is measured to the mid-point of the appropriate $8-\mathrm{cm}$ loop. Each loop was filled initially with 0.5 $\mathrm{ml}$ of taurocholate-saline medium (Methods) containing approximately $5 \mu \mathrm{g}$ of the appropriate sterol. Loops were excised after 5 hours and residual radioactivity estimated. The rats weighed 165 to $190 \mathrm{~g}$.

commercial preparations were equally effective. Sodium taurodeoxycholate and sodium taurochenodeoxycholate were less effective, yielding insignificant increases in the smaller group tested. Sodium lauryl sulfate, $0.04 \mathrm{M}$, markedly decreased the absorption. The three purified bile salts were tested further at a concentration of $0.01 \mathrm{M}$ in jejunal loops prepared in rats with intact common bile ducts. A single loop was tied in at least eight rats to test each bile salt. The relative effectiveness of the three salts in promoting absorption was $1.36 / 1.19 / 1.00$ for taurocholate/taurochenodeoxycholate/taurodeoxycholate $(\mathrm{p}<0.001$ for taurocholate-taurodeoxycholate difference; $\mathrm{p}<$ 0.01 for taurochenodeoxycholate-taurodeoxycholate; $\mathrm{p}<0.05$ for taurocholate-taurochenodeoxycholate).

Segment of intestine. The absorption of $\mathrm{H}^{3}$ vitamin $\mathrm{D}_{3}$ from loops in situ prepared from various segments of the small intestine was examined in each of four rats. The results illustrated in Figure 3 demonstrate that in each animal absorption occurred throughout the proximal threefourths of the small intestine, was maximal in the mid-jejunal segment, and decreased distally to minimal values in the terminal ileum. Loop experiments with $\mathrm{C}^{14}$-vitamin $\mathrm{D}_{2}$ confirmed this pattern of absorption. For comparison with vitamin $\mathrm{D}_{3}$ similar experiments were performed with $\mathrm{C}^{14}$-cholesterol; representative plots are shown in Figure 3. Cholesterol, too, was absorbed most effectively from loops in the proximal half of the small intestine, and absorption decreased progressively in the distal half. In the jejunum the absorption of labeled cholesterol was generally less than that of vitamin $\mathrm{D}_{3}$ (Figure 3), but the data do not permit a comparison of true absorption rates. $\mathrm{C}^{14}$-cholesterol is diluted by endogenous cholesterol in the gut wall (29), whereas $\mathrm{H}^{3}$-vitamin $\mathrm{D}_{3}$ is not significantly diluted in the quantities used.

Absorption of the labeled sterols was compared further in three lymph fistula rats. Each animal received $130 \mu \mathrm{g}$ of $\mathrm{H}^{3}$-vitamin $\mathrm{D}_{3}$ and of $\mathrm{C}^{14}$-cholesterol in ethanol/propylene glycol, and both isotopes were estimated in successive lymph samples. The initial lag period in absorption observed with vitamin D (Figure 2) was longer for $\mathrm{C}^{14}$-cholesterol. In one animal, for example, the maximal rate of absorption of $\mathrm{H}^{3}$-vitamin $\mathrm{D}_{3}$, i.e., $4.6 \%$ of the initial dose per hour, was observed in the 2- to 4-hour collection period. The corresponding maximal rate for $\mathrm{C}^{14}$-cholesterol, $3.5 \%$ per hour, was observed in the 4- to 6-hour period. A lag period for cholesterol of this magnitude has been noted by prior investigators $(30,31)$.

Sequential steps. The absorption of vitamin D from intestinal loops can be resolved into at least two steps, defined as follows. Step 1 is uptake of labeled vitamin from the lumen so that the radio-

TABLE III

Effect of various solubilizing agents on absorption of $\mathrm{H}^{3}$ vitamin $D_{3}$ from loops of jejunum

\begin{tabular}{|c|c|c|c|c|c|}
\hline \multirow[b]{2}{*}{ Compound tested } & \multirow[b]{2}{*}{$\begin{array}{l}\text { No. of } \\
\text { rats }\end{array}$} & \multicolumn{4}{|c|}{$\begin{array}{l}\mathrm{H}^{\mathbf{3}} \text {-vitamin } \mathrm{D}_{\mathbf{z}} \text { absorbed } \\
\text { (mean \% of ititial dose) }\end{array}$} \\
\hline & & \multicolumn{2}{|c|}{$\begin{array}{l}\text { Saline } \\
\text { vehicle }\end{array}$} & \multicolumn{2}{|c|}{$\begin{array}{c}\text { Compound } \\
\text { added }\end{array}$} \\
\hline \multirow{5}{*}{$\begin{array}{l}\text { Na taurocholate } \\
\text { Pure } \\
\text { Commercial } \\
\text { Na taurodeoxycholate } \\
\text { Na taurochenodeoxy- } \\
\text { cholate } \\
\text { Na lauryl sulfate }\end{array}$} & & $\%$ & $\%$ & $\%$ & $\%$ \\
\hline & 10 & 14.0 & & 29.0* & \\
\hline & 6 & & 14.5 & & 28.8 \\
\hline & 4 & 13.1 & & 16.7 & \\
\hline & $\begin{array}{l}2 \\
3\end{array}$ & $\begin{array}{l}14.5 \\
17.5\end{array}$ & & $\begin{array}{r}17.2 \\
6.8\end{array}$ & \\
\hline
\end{tabular}

* p $<0.001$ for the effect of taurocholate. Each loop was filled initially with approximately $5 \mu \mathrm{g}$ of $\mathrm{H}^{3}$-vitamin $\mathrm{D}_{3}$. 
activity cannot be washed from the mucosal surface with isotonic saline. Step 2 is transport from the gut wall chiefly to the lymph, measured as the decrease in total radioactivity of the loop. The following experiment was designed to compare the steps in various segments of the small intestine. One mid-jejunal and one distal ileal loop were tied in each rat and filled with isotonic salinetaurocholate solution containing $\mathrm{H}^{3}$-vitamin $\mathrm{D}_{3}$. At various intervals thereafter the animals were killed in groups of five, each loop excised and rinsed with $2.0 \mathrm{ml}$ of isotonic saline, and the jejunal and ileal rinse fluids and tissues pooled separately. After estimation of the radioactivity, step 1 was calculated as initial radioactivity in the loop minus final radioactivity in the rinse fluid, and step 2 as initial minus final radioactivity in the entire loop. The results illustrated in Figure 4 demonstrate that step 1 was more rapid than step 2 at both levels of the intestine, indicating a lag in the transport within the mucosa. Jejunum and ileum appeared to differ primarily in step 1 . The initial rate of step 1 was more rapid and the total uptake by the mucosa more complete in jejunum than in ileum. Step 2, in absolute units, was less in ileum than in jejunum, but expressed as a percentage of step 1 , the values at $4 \frac{1}{2}$ hours for jejunum and ileum, respectively, were 42.5 and $40.0 \%$, i.e., not significantly different.

Other factors. The effects of prior vitamin $\mathrm{D}$ depletion on absorption of $\mathrm{H}^{3}$-vitamin $\mathrm{D}_{3}$ from jejunal loops were examined with ten rats maintained on the vitamin D-free regimen (16) for 4 weeks. Four days before the experiment half the animals were given 20,000 IU vitamin $D_{3}$ subcutaneously. No significant difference in absorption between the treated and depleted animals was found. In a similar study with cortisone-treated (1.0 mg subcutaneously per day for 6 days) and untreated control rats, no difference in the subsequent absorption of $\mathrm{H}^{3}$-vitamin $\mathrm{D}_{3}$ from jejunal loops was noted.

\section{Discussion}

The preparation of tritiated vitamin $\mathrm{D}_{3}$ described in our present report is relatively simple and convenient, and the specific activity of the product is adequate for many metabolic studies. The material was recrystallized repeatedly as the

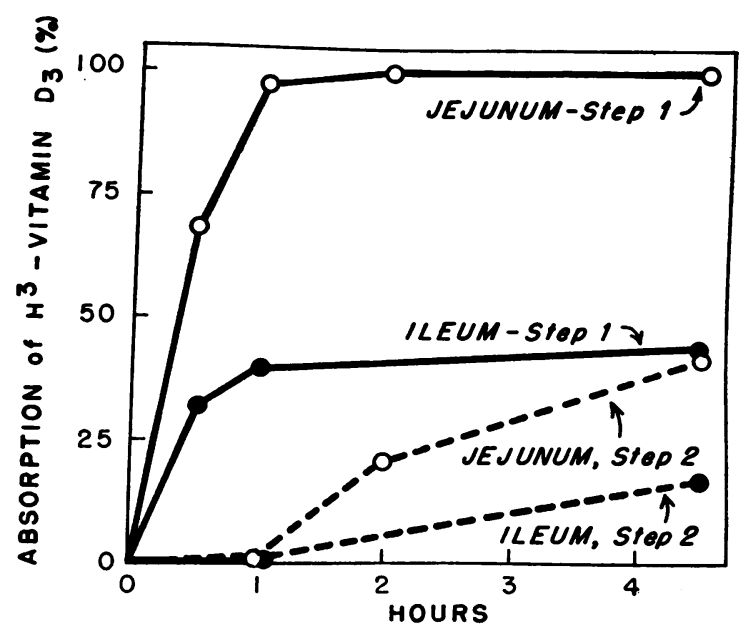

Fig. 4. Sequential Steps in abSoRption of $\mathrm{H}^{3}$-VItAMIN $D_{3}$ FRom intestinal LOOPS. Step 1 is uptake from the lumenal contents, and step 2 is transfer out of the loop, as defined in the text. Each loop was filled initially with $5 \mu \mathrm{g}$ of $\mathrm{H}^{3}$-vitamin $\mathrm{D}_{3}$ in taurocholate-saline medium. Rats weighed approximately $125 \mathrm{~g}$.

3,5-dinitrobenzoyl ester and, after hydrolysis, shown to be biologically fully active and chemically pure on gas-liquid chromatography. Moreover, the metabolism of $\mathrm{H}^{3}$-vitamin $\mathrm{D}_{3}$ in the experiments thus far has been generally similar to that of uniformly labeled $\mathrm{C}^{14}$-vitamin $\mathrm{D}_{2}$ prepared biosynthetically. As demonstrated above, both radioactive compounds are absorbed chiefly into lymph in the rat, and further studies in our laboratory (11) indicate that both are taken up mainly by liver and excreted into bile. The major pathways of transport and metabolism of the vitamins $\mathrm{D}$ are thus similar to those of cholesterol (32).

The present metabolic studies focus on the intestinal absorption of vitamin D. Our intestinal loop experiments clearly demonstrate that vitamin $\mathrm{D}$ can be absorbed throughout the proximal three-fourths of the rat small intestine, with maximal transport in the mid-jejunum and minimal absorption in the distal ileum. The absorption of cholesterol from loops shows a similar pattern, except that it is more restricted to the proximal half of the small intestine and decreases more rapidly in the distal half. The results with cholesterol confirm prior observations (30) of its maximal absorption in the upper jejunum of the rat in vivo. Further, the upper jejunum is the 
site of triglyceride absorption in man (33), and this segment is particularly effective in transport and esterification of $\mathrm{C}^{14}$-palmitate by everted sacs of hamster intestine (34). The jejunum, therefore, appears to be specialized for the absorption of several lipid substances. The results of our experiments do not support Kodicek's conclusion (35) that vitamin $\mathrm{D}$ is absorbed chiefly in the distal half of the rat small intestine. This conclusion was based on estimates of the vitamin $\mathrm{D}$ content of the intestinal wall after an oral dose. The content of vitamin $\mathrm{D}$ need not reflect the rate of absorption in a given segment, particularly many hours after the dose.

From the results of prior investigators (2628), we had expected the requirement for bile salt for vitamin D absorption. However, the greater effectiveness of taurocholate as compared to taurochenodeoxycholate and taurodeoxycholate is not readily explicable at present, except that normal rat bile does contain mainly taurocholate, with smaller quantities of taurochenodeoxycholate (36). We added the bile salts in great excess of vitamin $D_{3}$, and all yielded clear solutions to be tested. Thus optimal absorption of a lipid like vitamin $\mathrm{D}$ by rat intestinal mucosa may require prior solubilization as a micelle containing a specific bile salt. The bile salt requirement may also explain in part the poor absorption of sterols in the distal ileum. Experiments with loops of rat intestine in vivo (37) and everted gut sacs in vitro (38) have demonstrated that bile salts are absorbed principally in the distal ileum. The cellular sites responsible for this transport could strip micelles of their bile salt, thereby interfering with the absorption of sterols.

Although both cholesterol and vitamin D are absorbed into lymph and found mainly in the chylomicron fraction, the respective mechanisms clearly differ in that the major fraction of lymph cholesterol is esterified (30), whereas that of vitamin $\mathrm{D}$ is not. We compared the transport into lymph of small, equal doses of $\mathrm{C}^{14}$-cholesterol and $\mathrm{H}^{3}$-vitamin $\mathrm{D}_{3}$. The peak rate of transport of vitamin $\mathrm{D}$ exceeded that of $\mathrm{C}^{14}$-cholesterol, owing probably to dilution of the latter by endogenous pools in the intestine. In addition, the $\mathrm{C}^{14}$-cholesterol, as compared to vitamin $\mathrm{D}$, required more time to reach its peak transfer rate to lymph. This lag period could result from slow mixing in the endogenous cholesterol pools, from slow transfer between pools, or from a slow rate of esterification.

The cellular mechanisms responsible for sterol transport in the intestinal mucosa are poorly understood. Many investigators have emphasized the selective nature of the absorption. Glover and Morton (39) reviewed the evidence that several mammalian species absorb phytosterols poorly as compared to cholesterol and 7-dehydrocholesterol, whereas the compounds differ little in structure or lipid solubility. In our studies vitamin $\mathrm{D}_{2}$ was absorbed into lymph less rapidly than vita$\min \mathrm{D}_{3}$. Further evidence that sterol transport is a specialized cellular function is that cholesterol and vitamin $\mathrm{D}$ are absorbed more readily in proximal jejunum than in distal ileum and that taurocholate, in contrast to taurochenodeoxycholate and taurodeoxycholate, is required for optimal transfer of vitamin $D_{3}$ in the rat. Prior investigators (e.g., 31, 39, 40) have considered sterol absorption in two steps: 1) uptake at the mucosal surface and 2) transfer into lymph. Experiments with $\beta$-sitosterol (40) and tobacco leaf phytosterols (41) indicate that these sterols are taken up at the mucosal surface, although less readily than cholesterol, but only insignificant quantities are subsequently transferred to lymph. Thus both steps in sterol absorption appear to be relatively specific. Vitamin D absorption can also be resolved into a rapid mucosal uptake followed by a much slower transfer to the lymph. We demonstrated in the present studies, moreover, that jejunum and ileum differ in their absorption of the vitamin primarily in the first, mucosal uptake step. In view of such evidence, it is reasonable to suspect that cellular organelles play an active role in determining the specificity of sterol absorption. Although the specific transport sites may involve lipoproteins, as suggested by Glover and Green (42), there is as yet no direct evidence concerning the chemical nature of such sites.

\section{Summary}

Methods are described for the chemical preparation of $\mathrm{H}^{3}$-vitamin $\mathrm{D}_{3}$ and of uniformly labeled $\mathrm{C}^{14}$-vitamin $\mathrm{D}_{2}$ from $\mathrm{C}^{14}$-ergosterol synthesized by yeast. The intestinal absorption of the la- 
beled compounds was studied in vivo in the rat. Vitamin D is absorbed maximally in the jejunum and transferred chiefly into lymph. It was found mainly in the chylomicron fraction, as the free, biologically active sterol. Bile salt, specifically taurocholate as compared to taurodeoxycholate and taurochenodeoxycholate, is required for optimal absorption. Two steps can be distinguished in the transport across the intestine: uptake at the mucosal surface, relatively rapid, and transfer to lymph, relatively slow. Absorption is more rapid from mid-jejunal as compared to distal ileal segments primarily because the first, mucosal uptake step is more rapid and complete.

\section{Addendum}

Subsequent to the completion of this manuscript Norman and DeLuca (43) described a method for the preparation of the tritiated precursors of vitamins $D_{2}$ and $D_{3}$ and their irradiation to the active vitamins. After oral administration of $\mathrm{H}^{3}$-vitamin $\mathrm{D}_{3}$ in Wesson oil to rats, the ileum was found to contain more radioactivity than the more proximal small intestine, as observed previously by Kodicek (35). As noted in the Discussion, such observations do not test absorption directly, need not reflect the capacity of various segments of the intestine to absorb the vitamin, and are not directly comparable to the loop experiments described here.

\section{References}

1. Nicolaysen, R., N. Eeg-Larsen, and O. J. Malm. Physiology of calcium metabolism. Physiol. Rev. 1953, 33, 424.

2. Schachter, D., and S. M. Rosen. Active transport of $\mathrm{Ca}^{45}$ by the small intestine and its dependence on vitamin D. Amer. J. Physiol. 1959, 196, 357.

3. Dowdle, E. B., D. Schachter, and H. Schenker. Requirement for vitamin $\mathrm{D}$ for the active transport of calcium by the intestine. Amer. J. Physiol. 1960, 198, 269.

4. Schachter, D., D. V. Kimberg, and H. Schenker. Active transport of calcium by intestine: action and bio-assay of vitamin D. Amer. J. Physiol. 1961, 200, 1263.

5. Havinga, E., and J. P. L. Bots. Vitamin D and related compounds. I. The synthesis of vitamin- $\mathrm{D}_{3}$ 3-C ${ }^{14}$. Rec. trav. Chim. Pays-Bas 1954, 73, 393.

6. Kodicek, E. The biosynthesis of ${ }^{14} \mathrm{C}$-labelled ergocalciferol (abstract). Biochem. J. 1955, 60, 25 P.

7. Kodicek, E. Metabolic studies on vitamin D in Ciba Foundation Symposium on Bone Structure and Metabolism, G. E. W. Wolstenholme and C. M. O'Connor, Eds. London, J. \& A. Churchill, 1956, p. 161.
8. Kodicek, E., and D. R. Ashby. The metabolism of ${ }^{14} \mathrm{C}$-labelled vitamin $\mathrm{D}_{2}$ in the rat. Biochem. J. 1960, 75, 17 P.

9. Kodicek, E., and D. R. Ashby. The fate of physiological doses of ${ }^{14} \mathrm{C}$-labelled vitamin $\mathrm{D}_{2}$ in normal and rachitic rats. Biochem. J. 1960, 76, $14 \mathrm{P}$.

10. Innes Chalk, K. J., and E. Kodicek. The association of ${ }^{14} \mathrm{C}$-labelled vitamin $\mathrm{D}_{2}$ with rat serum proteins. Biochem. J. 1961, 79, 1.

11. Schachter, D., J. D. Finkelstein, and S. Kowarski. Pathways of transport and metabolism of $\mathrm{C}^{\mathbf{1 4}}$ vitamin $\mathrm{D}_{2}$ in the rat. J. clin. Invest. 1963, 42, 974.

12. DeWitt, J. B., and M. X. Sullivan. Spectrophotometric procedure for quantitative estimation of vitamins D. J. industr. eng. Chem., analyt. ed. 1946, 18, 117.

13. Brockmann, H. Die Isolierung des antirachitischen Vitamins aus Thunfischleberöl. Hoppe-Seylers Z. physiol. Chem. 1936, 241, 104.

14. Snyder, F., and N. Stephens. Quantitative carbon-14 and tritium assay of thin-layer chromatography plates. Analyt. Biochem. 1962, 4, 128.

15. Bray, G. A. A simple efficient liquid scintillator for counting aqueous solutions in a liquid scintillation counter. Analyt. Biochem. 1960, 1, 279.

16. Gordan, G. S., and D. Schachter. Vitamin D activity of normal and neoplastic breast tissue. Proc. Soc. exp. Biol. (N. Y.) 1963, 113, 760.

17. Ziffer, H., W. J. A. VandenHeuvel, E. O. A. Haahti, and E. C. Horning. Gas chromatographic behavior of vitamins $\mathrm{D}_{2}$ and $\mathrm{D}_{3}$. J. Amer. chem. Soc. 1960, 82, 6411.

18. Klosty, M., and W. Bergmann. Sterols of algae. III. The occurrence of ergosterol in Chlorella pyranoidosa. J. Amer. chem. Soc. 1952, 74, 1601.

19. Schoenheimer, R., and H. Dam. Ueber die Spaltbarkeit und Loeslichkeit von Sterindigittoniden. Hoppe-Seylers Z. physiol. Chem. 1933, 215, 59.

20. Velluz, L., A. Petit, G. Michel, and G. Rousseau. Sur un stade non photochimique dans la formation des calciférols. C. R. Acad. Sci. (Paris) 1948, 226, 1287.

21. Avigan, J., DeW. S. Goodman, and D. Steinberg. Thin-layer chromatography of sterols and steroids. J. Lipid Res. 1963, 4, 100.

22. Kodicek, E., E. M. Cruickshank, and D. R. Ashby. The metabolism of ${ }^{14} \mathrm{C}$-labelled vitamin $\mathrm{D}_{2}$ injected intracardially into rats. Biochem. J. 1960, 76, $15 \mathrm{P}$.

23. Bollman, J. L., J. C. Cain, and J. H. Grindlay. Techniques for the collection of lymph from the liver, small intestine, or thoracic duct of the rat. J. Lab. clin. Med. 1948, 33, 1349.

24. Manis, J. G., and D. Schachter. Active transport of iron by intestine: features of the two-step mechanism. Amer. J. Physiol. 1962, 203, 73.

25. Mangold, H. K. Thin-layer chromatography of lipids. J. oil chem. Soc. 1961, 38, 708. 
26. Greaves, J. D., and C. L. A. Schmidt. The role played by bile in the absorption of vitamin $\mathrm{D}$ in the rat. J. biol. Chem. 1933, 102, 101.

27. Taylor, N. B., C. B. Weld, and J. F. Sykes. The relation of bile to the absorption of vitamin D. Brit. J. exp. Path. 1935, 16, 302.

28. Heymann, W. Metabolism and mode of action of vitamin D. IV. Importance of bile in the absorption and excretion of vitamin D. J. biol. Chem. 1937, 122, 249.

29. Swell, L., E. C. Trout, Jr., J. R. Hopper, H. Field, Jr., and C. R. Treadwell. Mechanism of cholesterol absorption. II. Changes in free and esterified cholesterol pools of mucosa after feeding cholesterol-4-C ${ }^{14}$. J. biol. Chem. 1958, 233, 49.

30. Swell, L., E. C. Trout, Jr., J. R. Hopper, H. Field, Jr., and C. R. Treadwell. The mechanism of cholesterol absorption. Ann. N. Y. Acad. Sci. 1959, $72,813$.

31. Borgström, B., B-Å. Lindhe, and P. Wlodawer. Absorption and distribution of cholesterol-4-C $\mathrm{C}^{14}$ in the rat. Proc. Soc. exp. Biol. (N. Y.) 1958, 99, 365.

32. Gould, R. G., and R. P. Cook. The metabolism of cholesterol and other sterols in the animal organism in Cholesterol, Chemistry, Biochemistry, and $\mathrm{Pa}-$ thology, R. P. Cook, Ed. New York, Academic Press, 1958, p. 237.

33. Borgström, B., A. Dahlqvist, G. Lundh, and J. Sjövall. Studies of intestinal digestion and absorption in the human. J. clin. Invest. 1957, 36, 1521.
34. Johnston, J. M. Site of fatty acid absorption. Proc. Soc. exp. Biol. (N. Y.) 1959, 100, 669.

35. Kodicek, E. The metabolism of vitamin $\mathrm{D}$ in Vitamin Metabolism, Fourth International Congress of Biochemistry. London, Pergamon, 1958, vol. 11, p. 198.

36. Bergström, S., and J. Sjövall. Occurrence and metabolism of chenodesoxycholic acid in the rat. Bile acids and steroids 13 . Acta chem. scand. 1954, 8, 611.

37. Baker, R. D., and G. W. Searle. Bile salt absorption at various levels of rat small intestine. Proc. Soc. exp. Biol. (N. Y.) 1960, 105, 521.

38. Lack, L., and I. M. Weiner. In vitro absorption of bile salts by small intestine of rats and guinea pigs. Amer. J. Physiol. 1961, 200, 313.

39. Glover, J., and R. A. Morton. The absorption and metabolism of stero!s. Brit. med. Bull. 1958, 14, 226.

40. Swell, L., E. C. Trout, Jr., H. Fields, Jr., and C. R. Treadwell. Absorption of $\mathrm{H}^{3}$ - $\beta$-sitosterol in the lymph fistula rat. Proc. Soc. exp. Biol. (N. Y.) 1959, 100, 140.

41. Swell, L., E. C. Trout, Jr., H. Field, Jr., and C. R. Treadwell. Intestinal metabolism of $\mathrm{C}^{14}$-phytosterols. J. biol. Chem. 1959, 234, 2286.

42. Glover, J., and C. Green. Sterol metabolism. 3. The distribution and transport of sterols across the intestinal mucosa of the guinea pig. Biochem. J. 1957, 67, 308.

43. Norman, A. W., and H. F. DeLuca. The preparation of $\mathrm{H}^{3}$-vitamins $\mathrm{D}_{2}$ and $\mathrm{D}_{3}$ and their localization in the rat. Biochemistry 1963, 2, 1160. 